\title{
Oviposition preference of two hoverfly species in response to risk of intraguild predation
}

\author{
Nugroho Susetya Putra, ${ }^{1}$ Hironori Yasuda ${ }^{2, *}$ and Satoru SATo ${ }^{2}$ \\ ${ }^{1}$ The United Graduate School of Agriculture Science, Iwate University (assignment Yamagata University); Tsuruoka 997-8555, \\ Japan \\ ${ }^{2}$ Department of Agriculture, Yamagata University; Tsuruoka 997-8555, Japan \\ (Received 10 March 2008; Accepted 12 September 2008)
}

\begin{abstract}
Two experiments were performed in the laboratory to understand the relationships between oviposition preference and larval performance of the two predatory hoverfly species, Episyrphus balteatus de Geer and Metasyrphus corollae Fabricius. We first conducted laboratory experiments to understand the nature and relative strengths of intraguild predation between the larvae of three ladybird species, Harmonia axyridis Pallas, Propylea japonica Thunberg, and Scymnus posticalis Sicard, and two predatory hoverfly species. The interactions between larvae of the three ladybird and two hoverfly species differed depending on the species and developmental stages involved: the relationships between $H$. axyridis or $S$. posticalis and the two hoverfly larvae tended to be asymmetric with $H$. axyridis being a superior species and $S$. posticalis an inferior species, although the reverse was true for each of these two species when small larvae were paired with large larvae of the hoverflies. The ladybird, P. japonica, had both asymmetric and symmetric relationships depending on the hoverfly species with which it interacted. Secondly, we tested the preference and performance hypothesis for hoverflies, by determining whether hoverfly oviposition preference was related to the risk of intraguild predation posed by the presence of a ladybird larva in an aphid colony. Oviposition preference in relation to larval performance of the two hoverflies differed between the species: E. balteatus females tended to adjust their rate of eggs laying in response to the presence of ladybird larvae, while similar responses of $M$. corollae females were weak. The relationship between oviposition preference and larval performance in hoverflies is discussed.
\end{abstract}

Key words: Hoverfly; ladybird larvae; larval performance; oviposition response; risk of intraguild predation

\section{INTRODUCTION}

Understanding the relationships between oviposition preference and larval performance is one of most important issues in insect ecology since these relationships strongly influence individual fitness, population dynamics, and community structure (e.g., Blaustein et al., 2004; Craig and Ohgushi, 2002). In general, natural selection will favor females that lay eggs at a most appropriate site for offspring. To enhance their fitness, for instance, females of insects tend to choose an oviposition site that provides suitable food as well as reduced risk of predation, as achieved by avoiding patches containing potential predators (e.g., Sadeghi and Gilbert, 2000a, b; Blaustein et al., 2004). These relationships have been studied mainly in several taxonomic groups of phytophagous insects (e.g., Yamaga and Ohgushi, 1999; Mira and Bernays, 2002; Singer et al., 2004), and predatory insects as well (e.g., Doumbia et al., 1998; Nakashima et al., 2006).

It is well known that intraguild predators critically affect the larval fate of intraguild prey species among predatory insects (e.g., Lucas et al., 1998; Phoofolo and Obrycki, 1998; Hindayana et al., 2000). This in turn may influence oviposition site selection by these predators (e.g., Taylor et al., 1998; Takizawa et al., 2000). For example, a parasitoid wasp tends to avoid ovipositing in an aphid colony containing an intraguild predator (Takizawa et al., 2000), suggesting that intraguild prey species

\footnotetext{
* To whom correspondence should be addressed at: E-mail: hyasuda@tds1.tr.yamagata-u.ac.jp DOI: $10.1303 /$ aez.2009.29
} 
might avoid laying eggs in patches having potential intraguild predators. However, there are few studies to understand how an intraguild prey species chooses oviposition sites in relation to its intraguild predators.

Ladybirds and predatory hoverflies are common aphidophagous insects that often coexist with each other on the same plants, where the larvae of these species interact strongly each other as they face low food availability (e.g., Agarwala and Yasuda, 2001). Negative impacts of ladybird larvae on larval performances of aphidophagous insects have been reported for various taxonomic groups (e.g., Ferguson and Stiling, 1996; Lucas et al., 1998; Felix and Soares, 2004). In particular, ladybird larvae often reduce survivorship of related species in acting as intraguild predators (Yasuda and Ohnuma, 1999; Hindayana et al., 2000; Meyhofer and Hindayana, 2000). Hoverfly larvae are vulnerable to intraguild predation since the larvae have low mobility (e.g., Hindayana et al., 2000). This suggests that predatory hoverflies might prefer to lay eggs at sites with few predators in addition to many prey. Hoverfly females can recognize a suitable aphid colony at which they lay eggs (Kan and Sasakawa, 1986; Kan, 1988a,b), and they might have similarly strong oviposition preferences for sites in relation to intraguild predators. However, there are no studies to support this hypothesis (Gilbert, 2005).

We conducted a couple of laboratory experiments to understand larval interactions between the larvae of three ladybird species, Harmonia axyridis Pallas, Propylea japonica Thunberg, and Scymnus posticalis Sicard, and two predatory hoverfly species, Episyrphus balteatus de Geer and Metasyrphus corollae Fabricius. As these insects provided differ in size, foraging behavior, and food habit, these differences are likely important for larval interactions involving intraguild predation between the ladybirds and hoverflies (Lucas et al., 1998).

We examined first the nature and relative strengths of intraguild predation between different development stages of the three ladybird and two hoverfly larvae. We predicted that hoverfly larvae would most often serve as the prey due to their low mobility, although the outcome of interactions would also vary with larval stages as depend on their body size, aggressiveness and mobility. Sec- ondly, we tested the preference and performance hypothesis that the potential for intraguild predation by ladybird larvae on hoverfly larvae would affect oviposition preference of hoverfly females.

\section{MATERIALS AND METHODS}

Insect rearing. Adults of the two hoverfly species, E. balteatus and M. corollae, and three ladybird species, $H$. axyridis, $P$. japonica and $S$. posticalis, were collected from the Yamagata University farm and the Akagawa riverbank, Tsuruoka, Yamagata, Japan. Similar numbers of females and males of each hoverfly species were reared separately in two muslin cages $(60 \times 60 \times 70 \mathrm{~cm})$ with 20-30 adults of each species in total. Food for these adults was provided by putting crushedpollen in a Petri dish $(5 \mathrm{~cm}$ in diameter and $1 \mathrm{~cm}$ in height). Water and honey were provided for adults by inserting an aluminum stick ( $40 \mathrm{~cm}$ in length and $2 \mathrm{~mm}$ in diameter), with thin layer of honey on the upper part and towel paper wrapped on the lower part, through a small hole on the cap of a $500 \mathrm{ml}$ plastic bottle filled with water. Females and males were allowed to pair, and a couple of bean plant (Vicia faba) cuttings with Aphis craccivora Koch colonies were introduced into the cage as oviposition sites. Eggs were collected daily, and then were placed into a Petri dish until hatching. Hoverfly larvae were reared by providing ample numbers of $A$. craccivora as prey. A pair of adult ladybirds was kept in a Petri dish $(5 \mathrm{~cm}$ in diameter and $1 \mathrm{~cm}$ in height) and fed with Acyrthosiphon pisum (Harris) for $H$. axyridis and $P$. japonica, and A. craccivora for $S$. posticalis. Eggs were collected and the larvae hatching from these eggs were reared in similar fashion to the adults. All insects were maintained in a controlled room at $23^{\circ} \mathrm{C}, 75 \%$ relative humidity, and under a photoperiod of 16L8D.

Larval interaction between the two individuals of ladybirds and hoverflies. Of the three ladybird species, $H$. axyridis is the largest and most aggressive species that consumes not only aphids, but also other arthropods such as ladybird larvae, lepidopteran larvae, and spiders, in serving as a top predator in an aphidophagous guild (Yasuda and Shinya, 1997; Yasuda and Ohnuma, 1999; Sato et al., 2003). S. posticalis is the smallest and least mobile and $P$. japonica is intermediate in body size 
and mobility. The hoverflies, E. balteatus and $M$. corollae, are different in body size (Putra and Yasuda, 2006), but both are polyphagous species (Owen and Gilbert, 1989; Gilbert and Owen, 1990), although E. balteatus seems to have wider range of prey species.

To intensify the interactions between two individuals, larval interactions between the three ladybird and the two hoverfly species at different developmental stages were examined in the absence of extraguild prey. In order to understand these interactions, we used a small Petri dish $(5 \mathrm{~cm}$ in diameter and $1 \mathrm{~cm}$ in height) as an experimental arena. We tested combinations of ladybirds and hoverflies based on (1) larval developmental stages (early and late instars), and (2) species that differ in size, mobility, and aggressiveness, with 24 combinations in total and 15-20 replications for each combination.

Hoverfly and ladybird larvae were reared on plenty of aphids in a small Petri dish $(5 \mathrm{~cm}$ in diameter and $1 \mathrm{~cm}$ in height) as described above. The first instar larvae of the predatory insects were tested less than $12 \mathrm{~h}$ after they hatched, while the third instar larvae of the hoverfly and the fourth instar of ladybird larvae were tested within $24 \mathrm{~h}$ after molting. These predators were starved for $6 \mathrm{~h}$ prior to the experiment in order to increase hunger level, and the experiments were conducted in a controlled room as mentioned before for insect rearing.

A hoverfly larva was released in the Petri dish before releasing a ladybird larva in the same dish. The two larvae were allowed to interact for the next $24 \mathrm{~h}$. The outcome of the interactions was expressed as the percent of pairing in which intraguild predation occurred, since predation was observed in all combinations. Chi-square tests (Sokal and Rohlf, 1995) were performed to determine whether these interactions were symmetrical or not (i.e., whether ladybird and hoverfly larvae preyed on each other with equal frequency).

Effect of a ladybird larva on the oviposition preference of the two hoverfly species. The effect of a ladybird larva on the oviposition preference of a hoverfly female was examined by a non-choice test using 30 different gravid females for each species with the same age, i.e. 25-30 d after eclosion. A non-choice test was chosen since it enables the insect to perceive only one treatment, as shown in previous studies (Sadeghi and Gilbert, 2000b). A cutting of a bean plant $(20 \mathrm{~cm}$ in height $)$ which had been infested with 20-25 individuals of apterous $A$. craccivora at the apical portion was put into a bottle $(5 \mathrm{~cm}$ in height, and filled with water) to serve as an oviposition site. The cutting was covered with a cylindrical plastic cage $(8 \mathrm{~cm}$ in diameter and $42 \mathrm{~cm}$ in height). One gravid female was released into one replicate cage of each treatment as mentioned below for an hour. Since we applied seven treatments, each female was tested with the seven different types of oviposition sites, which were presented to the female in random order. The number of eggs laid on the bean plant in each treatment was counted. The seven treatments were arranged as follows, (1) an aphid colony without any ladybird larva as control, and (2) an aphid colony with a fresh-frozen ladybird larva that was (i) a first instar larva or (ii) a fourth instar larva of $H$. axyridis, (iii) a first instar larva or (iv) a fourth instar larva of $P$. japonica, and (v) a first instar larva or (vi) a fourth instar larva of $S$. posticalis. One-way ANOVA was performed on the number of eggs laid by a female among treatments, and means were compared by post-hoc Fisher LSD (Sokal and Rohlf, 1995).

\section{RESULTS}

\section{Larval interactions between the two individuals of ladybirds and hoverflies}

Among the three species of ladybirds, $H$. axyridis larvae most reduced survival of E. balteatus larvae (Fig. 1). For an equivalent larval stage, $H$. axyridis larvae were superior against the hoverfly larvae. Moreover, the first instar of hoverfly larvae was more vulnerable than the third instar larvae when confronted with $H$. axyridis larvae, and the first instar was always the victim in significantly asymmetric interactions with the ladybird larvae. The hoverfly larvae were superior only as third instars facing the first instar of $H$. axyridis larva. Interactions between E. balteatus and $P$. japonica larvae tended to result in asymmetric interactions, where first and third instar larvae of $E$. balteatus were prey and predator respectively when faced against the fourth and first instars of $P$. japonica. The other two interactions (L-1 vs L-1 and L-3 hoverfly vs L-4 ladybird) led to symmetric outcomes. Consequences of larval interactions between E. balteatus and S. posticalis were asymmetrical, with $E$. balteatus larvae significantly superior 
(a) E. balteatus vs. $H$. axyridis

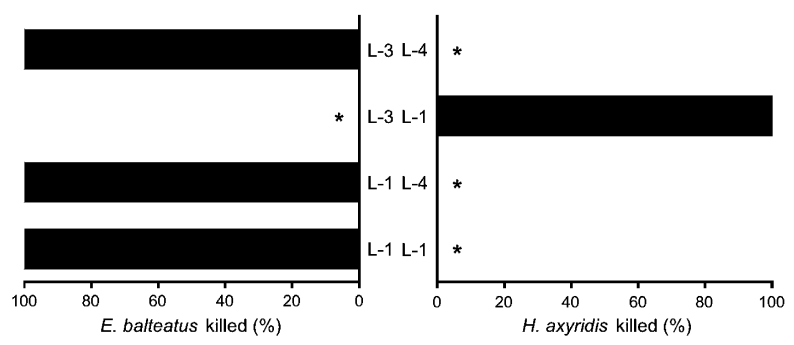

(b) E. balteatus vs. P. japonica

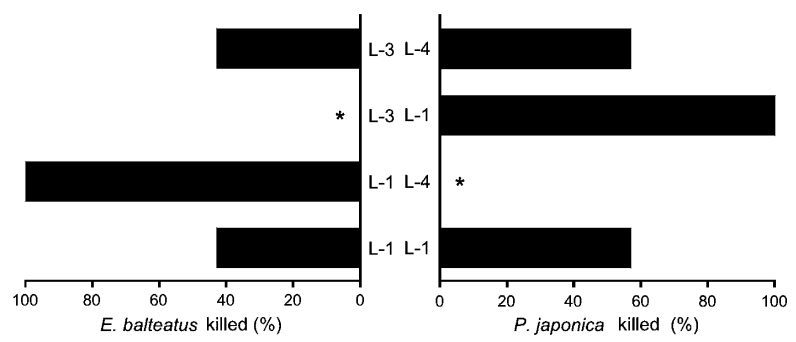

(c) E. balteatus vs. S. posticalis

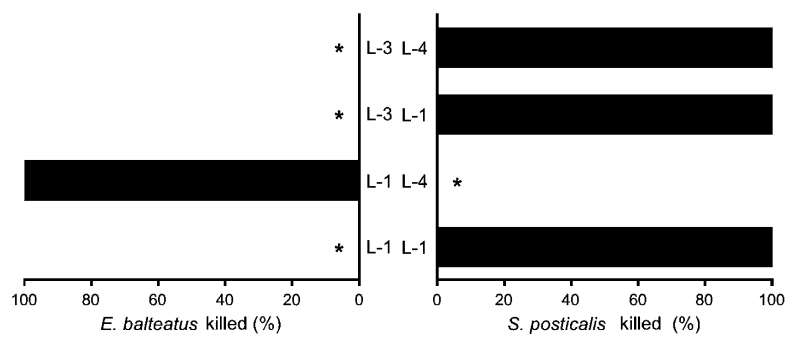

Fig. 1. Intraguild predation between the hoverfly, $E$. balteatus and three species of ladybirds, (a) H. axyridis, (b) $P$. japonica, and (c) $S$. posticalis at different developmental stages. Bars represent the percentage killed by each predator larva. Significant difference in the percentage is indicated with an asterisk ( $p<0.05$ for $\chi^{2}$ test). L-1, L-3, and L-4 are first, third, and fourth instar larva, respectively.

in three out of four combinations, but inferior when the first instar larva was paired with the fourth instar of $S$. posticalis larva.

Interactions between the other hoverfly, $M$. corollae, and the two ladybirds, $H$. axyridis and $P$. japonica larvae, were asymmetric, favoring the ladybird larvae (Fig. 2). The first instar of hoverfly larva was always vulnerable when faced with either the first and fourth instar of $H$. axyridis and $P$. japonica. M. corollae larvae were only superior when the third instar larva was paired with the first instar larva of the two ladybird species. When the hoverfly larva interacted with the $S$. posticalis larva, the hoverfly killed all the individuals of the ladybird larva in three out of four combinations. The ladybird larva always killed the hoverfly larva (a) M. corollae vs. $H$. axyridis

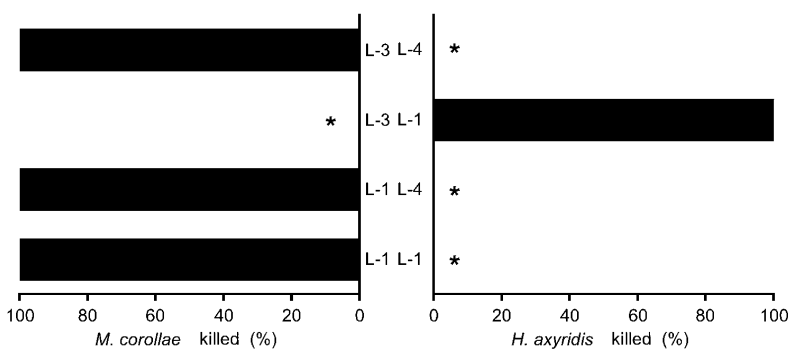

(b) M. corollae vs. P. japonica

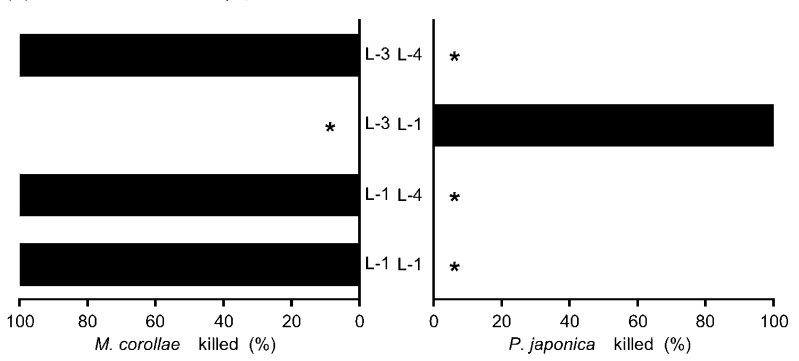

(c) M. corollae vs. S. posticalis

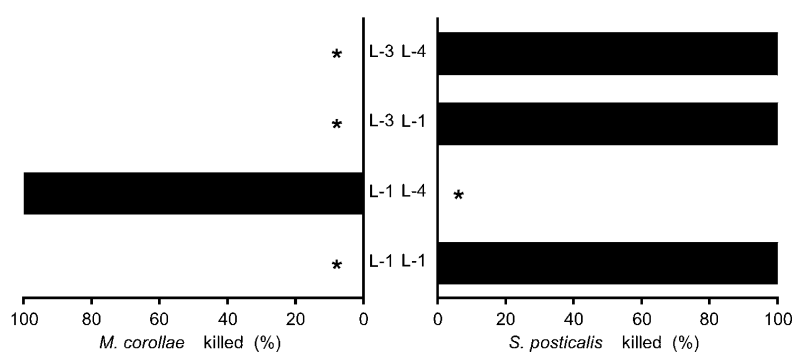

Fig. 2. Intraguild predation between the hoverfly, $M$. corollae and three species of ladybirds, (a) H. axyridis, (b) $P$. japonica, and (c) $S$. posticalis at different developmental stages. Bars represent the percentage killed by each predator larva. Significant difference in the percentage is indicated with an asterisk ( $p<0.05$ for $\chi^{2}$ test). L-1, L-3, and L-4 are first, third, and fourth instar larva, respectively.

when the fourth instar was paired with the first instar of hoverfly larva.

\section{Impact of a ladybird larva on the oviposition preference of the two hoverfly species}

The oviposition response of E. balteatus females on aphid colonies that also included a first or fourth instar of three ladybird species varied significantly among treatments (Fig. 3a; $F_{(6,203)}=3.55$, $p<0.05)$. E. balteatus females tended to lay fewer eggs in aphid colonies with a ladybird larva than without the larva. Furthermore, it seems that the presence of the fourth instar ladybird affected oviposition by the female hoverfly more negatively than did the presence of a first instar ladybird, al- 
(a) E. balteatus

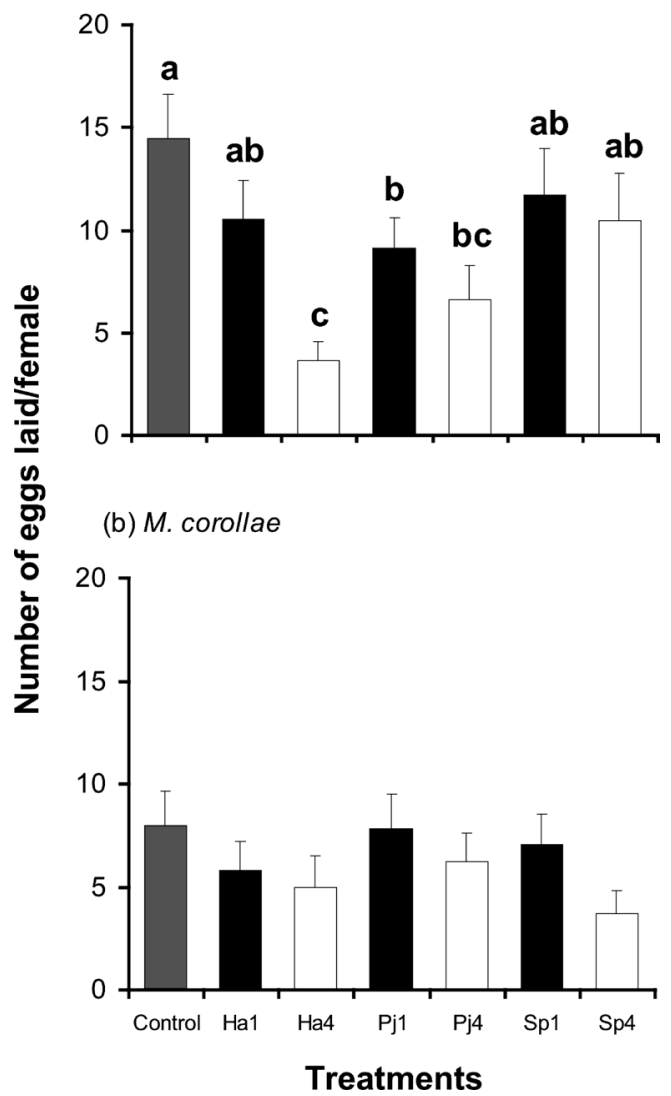

Fig. 3. Number of eggs laid by the two hoverflies, (a) $E$. balteatus and (b) M. corollae, as a response to the presence of each ladybird larva, H. axyridis $(\mathrm{Ha})$, P. japonica $(\mathrm{Pj})$, and $S$. posticalis (Sp). 1, 4, and control show the treatment with first, fourth instar larva, and without a larva, respectively. Different letters indicate significant difference among treatments $(p<0.05$ for Fisher LSD test).

though only the differences in the number of eggs laid between the control and the treatment with a fourth instar of $H$. axyridis and $P$. japonica were significant. The negative effect of the fourth instar larva of the ladybirds on the number of eggs laid by the female of $E$. balteatus was as follows: $H$. axyridis $>P$. japonica $>S$. posticalis. The response of the female of $M$. corollae to the treatments with a ladybird was weakly negative (Fig. $3 \mathrm{~b} ; F_{(6,203)}=$ $1.08, p>0.05)$, but again the negative response of the female to fourth instar larva tended to be stronger than to the first instar larva.

\section{DISCUSSION}

The results presented here reveal that the larval interactions between the three ladybird and two hoverfly larvae differed depending on the species and developmental stages involved. For instance, the relationships between $H$. axyridis or $S$. posticalis and the two hoverfly larvae tended to be asymmetric with $H$. axyridis prevailing over $S$. posticalis, although the opposite was true when the hoverfly was much older and larger than the ladybird. On the other hand, P. japonica had both asymmetric and symmetric relationships with hoverflies depending on the hoverfly species with which it interacted.

Intraguild predation is a well known phenomenon among the species that constitute an aphidophagous insect guild (Yasuda and Shinya, 1997; Snyder et al., 2004; Yasuda et al., 2004), and body size, aggressiveness, and voracity determine the outcome of the interaction between predatory arthropods (e.g. Lucas et al., 1998; Hindayana et al., 2000). In the experiments presented here, body size appears especially important, since the superiority in $H$. axyridis is attributable to it being the largest predator, while $S$. posticalis was inferior because it was the smallest predator. The size effect was also apparent in the interactions between $P$. japonica and the two hoverfly species in present study due to the difference in the size between the two hoverfly species (Putra and Yasuda, 2006). The fact that differences in developmental stages of the two individuals paired together resulted in asymmetric interactions also supports the importance of body size in influencing the outcome of interactions, as previously reported for a number of predators (Lucas et al., 1998; Hindayana et al., 2000; Snyder et al., 2004; Yasuda et al., 2004).

In addition to size, mobility is also regarded as an important factor influencing larval interactions, and species with higher mobility tend to have advantage in the interactions (Lucas et al., 1998). However, mobility appears less important than size in our experiments. Previous study revealed that $E$. balteatus larvae were aggressive against the predatory ladybird, Coccinella septempunctata larvae, which are similar to $H$. axyridis in size (Yasuda et al., 2004), and that $C$. septempunctata larvae were often preyed upon by the hoverfly larvae (Hindayana et al., 2000). This occurred despite the fact that $C$. septempunctata larvae are more mobile than E. balteatus larvae (Yasuda, personal observation). The different outcome of interactions be- 
tween $E$. balteatus and $C$. septempunctata and $H$. axyridis larvae seem attributable to differences not in size or mobility perse, but rather in aggressiveness and escape behavior between $H$. axyridis and C. septempunctata larvae (Yasuda et al., 2001, 2004).

Chemical and physical substances are well known to provide protection against attacks by predators (Völkl and Vohland, 1996). For example, hoverfly larvae produce sticky slime as physical defense (Gilbert, 1993). In our experiments, older larvae of $E$. balteatus may have benefited more from this substance than younger larvae because the older larvae produce larger amounts of the substance. Such may have been beneficial especially when these larvae were paired with weaker opponents such as $P$. japonica and $S$. posticalis larvae. However, when hoverflies were paired with fourth instars of $H$. axyridis, this slime did not protect hoverfly larvae from attacks. The substance produced by $M$. corollae may not work effectively as a defense because the small larvae of this species produce too little of sticky slime (Putra and Yasuda, 2006). S. posticalis larvae are covered with a waxy substance that functions as defense against ant attacks (Völkl and Vohland, 1996). However, in this study the waxy substance appeared ineffective as a defense against hoverflies, as the ladybird larvae were often preyed upon by the hoverfly larvae.

Oviposition preference in relation to larval performance of the two hoverflies differed between the species: E. balteatus females tended to reduce egg laying in response to the presense of ladybird larvae, while the response of $M$. corollae was weak. Oviposition preference of hoverfly species is well known to vary in response to development of an aphid colony (Kan and Sasakawa, 1986; Kan, $1988 \mathrm{a}, \mathrm{b}$ ) as well as to aphid quality (Sadeghi and Gilbert, 2000a, b). Thus, prey quantity and quality appear to strongly influence the oviposition behavior of hoverfly species.

In the present experiment, the hoverfly females also seemed to consider the potential risk of predation in patches such as a leaf and/or a plant. In general, arthropods tend to act to reduce the risks of being attacked or preyed by selecting an enemy free site for an oviposition site (Kanno and Harris, 2002; Mira and Bernays, 2002; Kiflawi et al., 2003). As shown in this study, E. balteatus females seem to consider both the species and developmen- tal stages of the ladybird larvae present at a potential oviposition site. As a result, E. balteatus laid fewest eggs at the aphid colonies which also had a $H$. axyridis larva, the strongest predator of the hoverfly larva. In addition, the number of eggs laid by an $E$. balteatus female was negatively related to the risk of predation. Interestingly, although the pattern of relative egg laying activity among treatments was similar for $M$. corollae as for E. balteatus females, but $M$. corollae females discriminated weakly among treatments such that insignificantly different numbers of eggs were laid among patches of different treatments. The difference in oviposition response between two hoverfly species was also apparent in relation to prey quality; however, the mechanism is still unclear (Sadeghi and Gilbert, 2000a, b). Therefore, the reason why the two species differed in oviposition response as shown in the present study should be addressed in future studies.

The mechanism of finding an oviposition site often appears to involve visible and chemical cues as important factors (Kan, 1988a,b; Blaustein et al., 2004). Hoverfly females recognized the developmental phase of aphids and the presence of the winged morph (Kan, 1988a, b), suggesting that $E$. balteatus females might detect the ladybird larva in an aphid colony by visible cues rather than by chemical cues.

Variation in the response of arthropods to predation risk for offspring is common. For example, some herbivorous insects choose low quality rather than high quality plant species in terms of larval performance, because the low quality plant provide opportunity for chemical defense against predators (Gross and Price, 1988; Denno et al., 1990; Mira and Bernays, 2002). That oviposition site selection may be important not only for phytophagous insects but also predatory insects is suggested by previous studies (Nomikou et al., 2003; Blaustein et al., 2004). Blaustein et al. (2004) reported that the oviposition response of two dipteran species to a hemipteran predator differed between the two species due to their vulnerabilities against the predator. Interestingly, the present study showed that $M$. corollae had a relatively weak oviposition response to the presence of intraguild predators, even though the vulnerability of $M$. corollae larvae to intraguild predation was higher than the vulnerability of $E$. balteatus larvae. Given the expectation that natural 
selection would favor strong oviposition responses when the threat of intraguild predation is high (Sadeghi and Gilbert, 2000a, b), M. corollae might not have a long history of coexistence with the ladybirds. This suggests that understanding the relationship of preference and performance requires consideration of the degree of coevolution between the related species.

\section{ACKNOWLEDGEMENTS}

We thank Professor Edward Evans (Utah State University) for helpful comments and improving English.

\section{REFERENCES}

Agarwala, B. K. and H. Yasuda (2001) Larval interactions in aphidophagous predators: effectiveness of wax cover as defense shield of Scymnus larvae against predation from syrphids. Entomol. Exp. Appl. 100: 101-107.

Blaustein, L., M. Kiflawi, A. Eitam, M. Mangel and J. E. Cohen (2004) Oviposition habitat selection in response to risk of predation in temporary pools: mode of detection and consistency across experimental venue. Oecologia 138: 300-305.

Craig, T. P. and T. Ohgushi (2002) Preference and performance are correlated in the spittlebug Aphrophora pectoralis on four species of willow. Ecol. Entomol. 27: 529-540.

Denno, R. F., S. Larsson and K. L. Olmstead (1990) Role of enemy-free space and quality in host-plant selection by willow beetles. Ecology 71: 124-137.

Doumbia, M., J.-L. Hemptinne and A. F. G. Dixon (1998) Assessment of patch quality by ladybirds: role of larval tracks. Oecologia 113: 197-202.

Felix, S. and A. O. Soares (2004) Intraguild predation between the aphidophagous ladybird beetles Harmonia axyridis and Coccinella undecimpunctata (Coleoptera: Coccinellidae): the role of body weight. Eur. J. Entomol. 101: 237-242.

Ferguson, K. I. and P. Stiling (1996) Non-additive effects of multiple natural enemies on aphid populations. Oecologia 108: $375-379$.

Gilbert, F. S. (1993) Hoverflies. Richmond Publishing Co. Ltd., Slought, England. 67 pp.

Gilbert, F. S. (2005) Syrphid aphidophagous predators in a food-web context. Eur. J. Entomol. 102: 325-333.

Gilbert, F. S. and J. Owen (1990) Size, shape, competition, and community structure in hoverflies (Diptera: Syrphidae). J. Anim. Ecol. 59: 21-39.

Gross, P. and P. W. Price (1988) Plant influences on parasitism of two leafminers - a test of enemy-free space. Ecology 69: 1506-1516.

Hindayana, D., R. Meyhofer, D. Scholz and H. M. Poehling (2000) Intraguild predation among the hoverfly Episyrphus balteatus de Geer (Diptera: Syrphidae) and other aphidophagous predators. Biol. Control 20: 236-246.

Kan, E. (1988a) Assessment of aphid colonies by hoverflies. I Maple aphids and Episyrphus balteatus (de Geer)
(Diptera: Syrphidae). J. Ethol. 6: 39-48.

Kan, E. (1988b) Assessment of aphid colonies by hoverfly. II Pea aphids and 3 syrphid species; Betasyrphus serarius (Wiedemann), Metasyrphus frequens Matsumura and Syrphus vitripennis (Meigen) (Diptera: Syrphidae). J. Ethol. 6: 135-142.

Kan, E. and M. Sasakawa (1986) Assessment of the maple aphid colony by the hover fly, Episyrphus balteatus (de Geer) (Diptera: Syrphidae) I. J. Ethol. 4: 121-127.

Kanno, H. and M. O. Harris (2002) Avoidance of occupied hosts by the Hessian fly: oviposition behavior and consequences for larval survival. Ecol. Entomol. 27: 177188.

Kiflawi, M., L. Blaustein and M. Mangel (2003) Oviposition habitat selection by the mosquito Culiseta longiareolata in response to risk of predation and conspecific larval density. Ecol. Entomol. 28: 168-173.

Lucas, E., D. Coderre and J. Brodeur (1998) Intraguild predation among aphid predators: characterization and influence of extraguild prey density. Ecology 79: 10841092.

Meyhofer, R. and D. Hindayana (2000) Effects of intraguild predation on aphid parasitoid survival. Entomol. Exp. Appl. 97: 115-122.

Mira, A. and E. A. Bernays (2002) Trade-off in host use by Manduca sexta: plant characters vs. natural enemies. Oikos 97: 387-397.

Nakashima, Y., M. A. Birkett, B. J. Pye and W. Powell (2006) Chemically mediated intraguild predator avoidance by aphid parasitoids: interspecific variability in sensitivity to semiochemical trails of ladybird predators. J. Chem. Ecol. 32: 1989-1998.

Nomikou, M., A. Janssen and M. W. Sabelis (2003) Herbivore host plant selection: whitefly learns to avoid host plants that harbor predators of her offspring. Oecologia 136: 484-488.

Owen, J. and F. S. Gilbert (1989) On the abundance of hoverflies (Syrphidae). Oikos 55: 183-193.

Phoofolo, M. W. and J. J. Obrycki (1998) Potential for intraguild predation and competition among predatory Coccinellidae and Chrysophidae. Entomol. Exp. Appl. 89: $47-55$.

Putra, N. S. and H. Yasuda (2006) Effect of prey species and its density on larval performance of two species of hoverfly larvae, Episyrphus balteatus de Geer and Eupeodes corollae Fabricius (Diptera: Syrphidae). Appl. Entomol. Zool. 41: 389-397.

Sadeghi, H. and F. Gilbert (2000a) Aphid suitability and its relationship to oviposition preference in predatory hoverflies. J. Anim. Ecol. 69: 117-125.

Sadeghi, H. and F. Gilbert (2000b) Oviposition preferences of aphidophagous hoverflies. Ecol. Entomol. 25: 91100.

Sato, S., A. F. G. Dixon and H. Yasuda (2003) Effect of emigration on cannibalism and intraguild predation in aphidophagous ladybirds. Ecol. Entomol. 28: 628-633.

Singer, M. S., D. Rodrigues, J. O. Stireman and Y. Carriere (2004) Roles of food quality and enemy-free space in host use by a generalist insect herbivore. Ecology 85: 
2747-2753.

Snyder, W. E., G. M. Clevenger and S. D. Eigenbrode (2004) Intraguild predation and successful invasion by introduced ladybird beetles. Oecologia 140: 559-565.

Sokal, R. R. and F. J. Rohlf (1995) Biometry. W. H. Freeman and Company, New York. 859 pp.

Takizawa, T., H. Yasuda and B. K. Agarwala (2000) Effect of three species of predatory ladybirds on oviposition of aphid parasitoids. Entomol. Sci. 3: 465-469.

Taylor, A. J., C. B. Muller and H. C. J. Godfray (1998) Effect of aphid predators on oviposition behavior of aphid parasitoids. J. Insect Behav. 11: 297-302.

Völkl, W. and K. Vohland (1996) Wax covers in larvae of two Scymnus species: do they enhance coccinellid larval survival? Oecologia 107: 498-503.

Yamaga, Y. and T. Ohgushi (1999) Preference-performance linkage in a herbivorous lady beetle: consequences of variability of natural enemies. Oecologia 119: 183-190.

Yasuda, H. and N. Ohnuma (1999) Effect of cannibalism and predation on the larval performance of two ladybird beetles. Entomol. Exp. Appl. 93: 63-67.

Yasuda, H. and K. Shinya (1997) Cannibalism and interspecific predation in two predatory ladybirds in relation to prey abundance in the field. Entomophaga 42: 153-163.

Yasuda, H., T. Kikuchi, P. Kindlmann and S. Sato (2001) Relationship between attack and escape rates, cannibalism, and intraguild predation in larvae of two predatory ladybirds. J. Insect Behav. 14: 373-384.

Yasuda, H., E. W. Evans, Y. Kajita, K. Urakawa and T. Takizawa (2004) Asymmetric larval interactions between introduced and indigenous ladybirds in North America. Oecologia 141: 722-731. 